\title{
IMPLEMENTASI BOARD GAMES DAN PENGARUHNYA TERHADAP HASIL BELAJAR BAHASA INGGRIS
}

\author{
Ni Made Ratminingsih \\ Jurusan Pendidikan Bahasa Inggris, Universitas Pendidikan Ganesha, Jl. Udayana No. 11 Singaraja \\ e-mail: made_ratminingsih@yahoo.com.au
}

\begin{abstract}
Implementation of Board Games and its Effect on Students' English Learning Achievement. This study is an experimental research which aims at investigating the effect of board games on students' English learning achievement. The population of this research was all elementary schools in 9 districts of Buleleng Regency determined by intact group random sampling taken using lottery. There were 12 experimental groups and 12 control groups which consisted of 681 students of grade 4, 5 and 6 representing 4 areas of eastern, western, northern, and sourthern Buleleng Regency. The experimental groups were taught with board games, while the control groups were taught without board games. The data were analyzed non-parametrically using Kruskal Wallis and Mann-Whitney. The results prove that board games have an effect on the students' English learning achievement.
\end{abstract}

Keywords: board games, learning achievement, primary school

\begin{abstract}
Abstrak: Implementasi Board Games dan pengaruhnya terhadap Hasil Belajar Bahasa Inggris. Penelitian ini merupakan penelitian eksperimental yang menginvestigasi pengaruh board games terhadap hasil belajar bahasa Inggris siswa. Populasi penelitian adalah sekolah dasar di 9 kecamatan di Kabupaten Buleleng, yang ditentukan dengan menggunakan intact group random sampling berdasarkan lotere. Terdapat 12 kelompok eksperimental dan 12 kelompok kontrol yang berjumlah 681 siswa kelas 4, 5, dan 6 yang mewakili 4 area Kabupaten Buleleng Timur, Barat, Utara dan Selatan. Kelompok eksperimental mendapatkan tindakan, yaitu diajar dengan menggunakan board games, sedangkan kelompok kontrol diajar dengan tanpa menggunakan board games. Data dianalisis secara non parametrik dengan menggunakan analisis Kruskal Wallis dan Mann-Whitney. Hasil penelitian membuktikan bahwa board games berpengaruh terhadap peningkatan hasil belajar Bahasa Inggris siswa.
\end{abstract}

Kata kunci: board games, hasil belajar, sekolah dasar

Pembelajaran Bahasa Inggris untuk anak-anak (TEYL) di sekolah dasar memang sangat perlu diperkenalkan sejak dini, karena anak-anak memiliki kemampuan untuk mengingat lebih baik daripada orang dewasa. Hal ini juga dikatakan dalam berbagai teori SLA bahwa anak-anak memiliki perangkat pemerolehan bahasa (language acquisition device) yang masih segar, sehingga mereka dapat memahami bahasa dengan lebih cepat. Pengenalan lebih awal tersebut dianggap lebih baik karena belajar bahasa sampai dengan umur 12 tahun dikatakan sebagai golden years, yang dapat menjadi fondasi kecakapan berbahasa. Seorang ahli linguistik (Schmid, 2016) menyatakan bahwa berbagai penelitian telah membuktikan belajar bahasa kedua (asing) lebih baik dilakukan pada usia anak-anak yang dinamakan “critical period" karena kapasitas otak akan menu- run seiring waktu. Gawi (2012) dan Munoz (2014) menegaskan bahwa pengenalan bahasa Inggris pada usia dini memberikan lebih banyak keuntungan, yakni semakin dini belajar, semakin baik mereka dalam proses dan hasil belajar. Gawi (2012), Mart (2012) dan Hosni (2014) juga menekankan bahwa pengenalan bahasa Inggris sejak dini tersebut penting, karena dapat membangun motivasi belajar bahasa dan mengembangkan kepekaan terhadap kebermanfaatan penggunaan bahasa Inggris dari awal. Berdasarkan fakta tersebut, pengenalan Bahasa Inggris sejak dini hendaknya tidak ditunda. Pemerolehan bahasa Inggris sejak dini bukan hanya berguna untuk mengembangkan kecakapan berkomunikasi, tetapi juga untuk pengembangan kognitif.

Terkait dengan diberlakukannya kurikulum 2013, pembelajaran Bahasa Inggris tidak diatur se- 
cara formal oleh pemerintah dalam struktur kurikulum sekolah dasar, namun dapat diajarkan sebagai muatan lokal atau ekstra kurikuler. Secara yuridis, Permen No 22 tahun 2006 (BSNP, 2006) tentang standar isi menegaskan bahwa pembelajaran bahasa Inggris di sekolah dasar adalah untuk (1) "mengembangkan kompetensi berkomunikasi dalam bentuk lisan secara terbatas untuk mengiringi tindakan (language accompanying action) dalam konteks sekolah, dan (2) memiliki kesadaran tentang hakikat dan pentingnya bahasa Inggris untuk meningkatkan daya saing bangsa dalam masyarakat global.” Jadi, kompetensi lisan lebih ditekankan daripada kompetensi tertulis, yang mencakup mendengarkan (listening) dan berbicara (speaking). Kompetensi menurut Kurikulum 2013 mencakup pengetahuan, keterampilan, sikap yang harus diajarkan secara holistik. Untuk mengukur ketercapaian pengetahuan kebahasaan, seperti kosakata dan aturan gramatika, yang menjadi fondasi dari keterampilan berkomunikasi, maka penelitian ini difokuskan pada hasil belajar siswa yang berwujud skor baik berupa angka atau persentase yang diperoleh setelah mengikuti proses belajar (Awan, Noureen \& Naz, 2011) yang menunjukkan kesuksesan peserta didik dalam menguasai materi yang diajarkaan termasuk di dalamnya pengetahuan procedural dan deklaratif (Feng, Fan, \& Yan, 2013; Kpolovie, Joe, \& Okoto, 2014). Dapat disimpulkan bahwa hasil belajar adalah skor yang dicapai oleh peserta didik anak-anak di sekolah dasar yang telah mempelajari sejumlah materi Bahasa Inggris baik mencakup kosakata dan aturan gramatika yang berupa pengetahuan procedural dan pengetahuan deklaratif yang ditentukan melalui hasil tes akhir berupa skor numerik.

Dalam usaha memfasilitasi peserta didik untuk memaksimalkan hasil belajar, metode, strategi dan media pembelajaran memegang peran sentral. Pembelajaran dapat berhasil baik apabila dilakukan dengan cara dan media yang tepat. Penggunan cara dan media yang tepat akan berhasil dilakukan apabila didukung oleh tenaga pengajar yang handal. Namun demikian, hasil survei Ratminingsih (2012) membuktikan bahwa masih banyak guru $(43,25 \%)$ yang belum memiliki kompetensi yang memadai untuk mengajarkan bahasa Inggris karena mereka mayoritas adalah guru kelas, yang tidak memiliki latar belakang pendidikan Bahasa Inggris. Mereka mengajar fokus pada buku teks/LKS yang digunakan. Data ini membuktikan bahwa guru berpatokan pada penggunaan buku teks atau LKS dalam mengajar dengan lebih banyak menggunakan metode ceramah. Hasil studi dokumen dan observasi kelas
(Ratminingsih \& Budasi, 2015) membuktikan bahwa metode yang sering digunakan oleh guru dalam mengajar adalah Grammar Translation Method, Direct Instruction, Audio Lingual Method. Strategi atau teknik pembelajarannya didominasi oleh penggunaan terjemahan, ceramah yakni dalam bentuk penjelasan materi pelajaran dalam bahasa Indonesia, dan latihan pengulangan (repetition drill). Guru menjadi pemeran dominan yang aktif menjelaskan pelajaran dan kurang mampu memvariasikan strategi pembelajaran yang dapat mendorong dan memotivasi anak-anak berpartisipasi aktif dalam menggunakan bahasa Inggris yang dipelajari dalam konteks pembelajaran yang menantang, mendorong siswa aktif berpartisipasi, dan menyenangkan. Cara mengajar yang kurang bervariasi dan menantang bahkan terpaku pada penggunan buku teks saja dapat membuat peserta didik tidak mempunyai ketertarikan terhadap pelajaran dan menjadi cepat bosan dalam belajar. Ramendra dan Ratminingsih (2007) menegaskan bahwa verbalisasi semata dalam pembelajaran menyebabkan peserta didik kurang mampu memahami pelajaran, karena anak-anak secara fisik selalu aktif, sehingga membutuhkan aktivitas yang membuat mereka bergerak. Oleh karena itu, dominasi guru dalam pembelajaran harus diminimalkan, sementara peran aktif siswa harus dimaksimalkan melalui cara yang menyenangkan dan menantang. Sehubungan dengan itu, Erdogan, Bayram, dan Deniz (2008), Garrett (2008), Thanh (2010) menjelaskan bahwa pembelajaran yang berpusat pada guru harus diubah dan direformasi untuk memberikan lingkungan belajar yang menyenangkan, aktivitas yang bermakna, kesempatan berkomunikasi secara efektif, belajar dengan bekerjasama, dan belajar mandiri.

Dengan demikian, menjadi kewajiban guru untuk memahami karakter peserta didik agar mereka dapat belajar maksimal. Menurut Kpolovie, dkk. (2014), faktor psikologis seperti ketertarikan (perhatian dan rasa keingintahuan) dan sikap mereka terhadap pembelajaran dapat berpengaruh terhadap hasil belajar. Oleh karenanya, guru hendaknya mampu menemukan metode, strategi/teknik, dan media yang sesuai dengan karakteristik peserta didik anakanak dalam mengoptimalkan proses pembelajaran, sehingga peserta didik anak-anak mampu mencapai hasil belajar yang sesuai dengan tujuan. Ana dan Ratminingsih (2012) dan Ratminingsih (2014) menekankan bahwa pembelajaran untuk anak-anak hendaknya difokuskan bukan hanya pada apa yang dipelajari, tetapi juga yang lebih penting adalah bagaimana mempelajarinya dari lingkungan sekitar 
agar hasil belajar maksimal melalui cara yang menyenangkan dan menantang mereka untuk terlibat aktif dalam proses pembelajaran.

Games adalah salah satu media pembelajaran yang dapat membantu atau memfasilitasi guru dalam menyampaikan materi pelajaran agar mudah dicerna oleh peserta didik (Rao, 2014). Syandri (2015) menambahkan bahwa penggunaan media bertujuan untuk membuat pembelajaran lebih efektif dan efisien serta dapat meningkatkan kualitas. Agar penggunaan media berhasil maksimal, Benzies (2015) menjelaskan bahwa pemilihan strategi dan media pembelajaran hendaknya dapat menarik perhatian peserta didik untuk terlibat belajar dalam konteks yang menyenangkan. Willing (dalam Chitravelu, Sithamparam \& Choon, 2005) menegaskan bahwa anak-anak yang yang bertipe kongkrit (concrete learner) menyenangi strategi pembelajaran yang memanfaatkan games, pictures, films, cassettes, videos, dan lain-lain. Dengan games peserta didik dapat belajar sambil bermain dan berinteraksi satu dengan yang lain. Dengan games, mereka dapat didorong untuk belajar optimal secara partisipatif dalam kegiatan-kegiatan individu, berpasangan atau kelompok kecil, mereka aktif menemukan konsep bahasa yang diajarkan yang dikemas dalam bentuk games. Dalam situasi belajar yang menyenangkan tersebut, anak-anak dapat dioptimalkan dalam mempelajari pengetahuan atau keterampilan baru, sehingga tujuan pembelajaran secara efektif dapat tercapai.

Banyak pakar telah membuktikan berbagai peranan strategi pembelajaran yang memanfaatkan games dalam pembelajaran. Feez (2010) mengemukakan bahwa games merupakan fondasi bagi semua pembelajaran pada anak-anak. Dalam pembelajaran bahasa, Paul (2003) menyatakan bahwa games adalah salah satu cara terbaik untuk membuat anak-anak terlibat secara mendalam dalam pembelajaran, bukan hanya untuk mempraktekkan bahasa, tetapi juga tempat terjadinya pembelajaran yang paling efektif. Wright, Betteridge, dan Buckby (2006) dan Ersoz (2008) menjelaskan bahwa games dapat membantu dan mendorong mereka mempertahankan ketertarikan dan aktivitas belajarnya. Games dapat membantu guru untuk menciptakan konteks kebahasaan yang membuat bahasa tersebut berguna dan bermakna. Dalam kegiatan pembelajaran dengan games, mereka dapat berpartisipasi aktif untuk belajar memahami apa yang dikatakan atau ditulis orang lain. Mereka juga harus belajar berbicara dan menulis, agar dapat mengekspresikan pandangan dan memberikan informasi. Games dapat menjadi sarana yang membantu mereka mengalami bahasa dan tidak sekadar mempelajari bahasa. Ersoz (2008) lebih lanjut mengungkapkan bahwa games yang dipilih dengan baik merupakan strategi belajar yang bermanfaat, oleh karena games dapat mendorong siswa mempraktekkan semua keterampilan berbahasa dan berbagai tipe komunikasi. Games sangat memotivasi karena games itu menarik dan menantang siswa. Brewster, Ellis, dan Girard (2007) menjelaskan manfaat games bukan hanya untuk perkembangan kognitif, tetapi juga psikomotor, dan afektif. Dengan kata lain, games bermanfaat bukan hanya memberikan kesenangan dalam belajar, mempertahankan ketertarikan dalam belajar, namun yang lebih penting adalah games memberikan pajanan linguistik dan mengembangkan kognitif, psikomotor, afektif, dan sosial siswa.

Brewster, dkk. (2007) membagi games dalam dua tipe utama, yakni (1) accuracy-focused games, dan (2) fluency-focused games. Dalam accuracyfocused games, siswa tidak perlu mengatakan sesuatu, mereka cukup hanya mendengar atau membaca kata-kata atau pola kalimat secara berulangulang. Sementara itu, dalam fluency-focused games fokus pembelajaran berada pada kelancaran dan kolaborasi dengan teman lain yang biasanya dilakukan secara berpasangan atau berkelompok. Dalam penelitian ini, peneliti mengkombinasikan kedua jenis games dalam bentuk board games yang dikembangkan oleh peneliti (Ratminingsih \& Budasi, 2015) yang disesuaikan dengan tema-tema yang harus diajarkan di kelas 4, 5, dan 6 sekolah dasar. Naz dan Akbar (2008) mengklasifikasikan board games sebagai salah satu dari tipe media simulasi dan permainan, dan menurut Berland dan Lee (2012), board games merupakan sebuah permainan yang menyediakan aktivitas yang sifatnya rekreatif, dimainkan secara berkelompok, dan dapat mengarahkan mereka bermain secara kompetitif, kooperatif, dan kolaboratif. Sejalan dengan itu, Zagal, Rick, dan His (2006) menyatakan bahwa board games memiliki potensi unik yang dapat membuat peserta didik berkolaborasi. Selanjutnya, Lee (2012) mengemukakan bahwa board games memiliki banyak keuntungan dalam pembelajaran bahasa, sepanjang guru menentukan dengan jelas aspek kebahasaan yang akan dipelajari oleh peserta didik. Sauve, Kaufman, dan Marquis (2007) mengklasifikasikan 11 jenis games untuk belajar bahasa. Di antara games tersebut ada games yang dimainkan dalam kelompok besar atau kecil. Board games yang diteliti dalam penelitian ini dilakukan baik dalam kelompok kecil maupun dalam kelompok besar. 
Empat jenis board games yang diteliti adalah Monopoly, Snake and Ladder, Jigsaw Puzzle, dan Kim's. Permainan Monopoly melibatkan pengambilan berbagai macam keputusan, seperti membeli atau tidak membeli properti, membuat perjanjian atau kesepakatan, dan lain sebagainya (Moursund, 2007). Salah satu keuntungan dari permainan ini dalam pembelajaran bahasa adalah dalam kemampuan membaca. Snake and Ladder game adalah permainan anak-anak yang membuat mereka belajar berhitung dan kosakata dengan memindahkan pion pada papan permainan yang berisi gambar tangga dan ular (Oktavianingsih, 2012). Puzzle game adalah permainan yang membuat anak-anak berpikir kritis dalam memecahkan masalah. Dalam permainan ini, pemain harus menyusun potonganpotongan gambar menjadi suatu gambar yang utuh. Kim's adalah permainan yang menggunakan beberapa kartu yang berisi gambar. Permainan ini melatih siswa mengingat kata sebanyak mungkin dan belajar menuliskan kata dengan ejaan yang benar (Wright, 2006).

Berdasar paparan di atas, dapat disampaikan bahwa tujuan dari penelitian ini adalah untuk menemukan apakah terdapat pengaruh signifikan pemanfaatan board games (Monopoly, Snake and Ladder, Puzzle, dan Kim's) terhadap hasil belajar Bahasa Inggris siswa di sekolah dasar.

\section{METODE}

Penelitian ini merupakan penelitian quasi experimental yang menggunakan rancangan post-test only control design. Populasi penelitian ini adalah semua SD di 9 kecamatan di Kabupaten Buleleng yang ditentukan dengan menggunakan intact group random sampling berdasarkan lotere, yang mewakili 4 area Kabupaten Buleleng, yaitu Timur, Barat, Utara, dan Selatan. Dari hasil sampling, terdapat 12 kelompok eksperimental, yaitu yang diberikan tindakan berupa pembelajaran dengan menggunakan 4 jenis board games yang berbeda, yaitu Monopoly, Snake and Ladder, Puzzle, dan Kim's di kelas 4, 5 dan 6, sedangkan 12 kelompok kontrol diajar tanpa board games atau pembelajaran konvensional, yaitu pembelajaran yang berjalan seperti biasa dengan menggunakan strategi dan media buku teks yang digunakan oleh guru secara reguler. Pemberi tindakan adalah 12 mahasiswa yang menjadi bagian dari payung penelitian yang telah dibimbing dan diarahkan untuk memperlakukan siswa baik kelompok eksperimental dan kontrol berdasarkan prosedur langkah-langkah pembelajaran yang ditetapkan. Sebelum diberikan tindakan, kesetaraan kompetensi kedua kelompok yang dibandingkan (12 kelompok eksperimental dan 12 kelompok kontrol) dipastikan dengan melakukan uji normalitas dan homoginitas terhadap nilai sumatif Bahasa Inggris di sekolah. Instrumen penelitian menggunakan tes, yaitu tes hasil belajar yang meliputi topik yang diajarkan sebanyak 6 kali pertemuan di masing-masing kelas. Tes diuji validitas kontennya oleh ahli dengan menggunakan formula Gregory dan kemudian divalidasi secara empiris melalui try-out untuk mencari validitas dengan analisis korelasi point biserial dan reliabilitasnya dengan analisis Kuder Richardson 20. Data kemudian dianalisis secara deskriptif dan inferensial. Secara deskriptif, data dideskripsikan dengan mengukur tendensi sentral, yaitu mean, median, standar deviasi, dan variansi. Sedangkan secara inferensial data dianalisis dengan analisis non parametrik, yaitu Kruskal Wallis untuk mencari pengaruh boards games terhadap hasil belajar, dan MannWhitney untuk menentukan pengaruh masingmasing jenis board games terhadap hasil belajar. Setelah itu efektivitas masing-masing jenis board games dapat ditentukan.

\section{HASIL DAN PEMBAHASAN}

\section{Hasil}

Berdasarkan Tabel 1 dapat dilihat bahwa dari total jumlah siswa 350 orang, setelah diberikan pembelajaran dengan menggunakan board games, skor rerata hasil belajar mereka adalah 82,79 , sedangkan siswa yang diajar tanpa board games mendapatkan skor rerata 74, 29. Data ini mengindikasikan bahwa siswa yang diajar menggunakan board games memperoleh skor yang lebih tinggi dibandingkan dengan yang belajar tanpa board games.

Tabel 1. Penggunaan Board Games dan Non Board Games

\begin{tabular}{lllrrrrrr}
\hline \multicolumn{1}{c}{ Group } & $\boldsymbol{N}$ & \multicolumn{1}{c}{ Mean } & \multicolumn{1}{c}{ Median } & Variance & Std. Deviation & Minimum & Maximum & Range \\
\hline $\begin{array}{l}\text { Experimental } \\
\text { Group }\end{array}$ & 350 & 82,7971 & 83 & 84,443 & 9,18929 & 54 & 100 & 46 \\
Control Group & 331 & 74,2931 & 74 & 123,82 & 11,12744 & 41 & 98 & 57 \\
\hline
\end{tabular}


Tabel 2. Penggunaan Monopoly Board Game dan Non Board Game

\begin{tabular}{lrrrrrrrr}
\hline \multicolumn{1}{c}{ Group } & $\boldsymbol{N}$ & \multicolumn{1}{c}{ Mean } & \multicolumn{1}{c}{ Median } & Variance & Std. Deviation & Minimum & Maximum & Range \\
\hline $\begin{array}{l}\text { Experimental } \\
\text { Group }\end{array}$ & 85 & 84,3059 & 85 & 78,001 & 8,83179 & 65 & 98 & 33 \\
Control Group & 87 & 72,9195 & 73 & 147,145 & 12,13032 & 46 & 93 & 47 \\
\hline
\end{tabular}

Tabel 3. Penggunaan Jigsaw Puzzle Board Game dan Non Board Game

\begin{tabular}{lccrrrrrr}
\hline \multicolumn{1}{c}{ Group } & $\boldsymbol{N}$ & \multicolumn{1}{c}{ Mean } & \multicolumn{1}{c}{ Median } & Variance & Std. Deviation & Minimum & Maximum & Range \\
\hline $\begin{array}{l}\text { Experimental } \\
\text { Group }\end{array}$ & 101 & 81,3366 & 82 & 93,306 & 9,68948 & 54 & 100 & 46 \\
Control Group & 93 & 72,2473 & 72 & 136,145 & 11,66811 & 41 & 98 & 57 \\
\hline
\end{tabular}

Tabel 4. Penggunaan Kim's Board Game dan Non Board Game

\begin{tabular}{lrrrrrrrr}
\hline \multicolumn{1}{c}{ Group } & \multicolumn{1}{c}{$\boldsymbol{N}$} & \multicolumn{1}{c}{ Mean } & \multicolumn{1}{c}{ Median } & Variance & \multicolumn{1}{c}{ Std. Deviation } & Minimum & Maximum & Range \\
\hline $\begin{array}{l}\text { Experimental } \\
\text { Group }\end{array}$ & 92 & 82,6739 & 82,5 & 64,178 & 8,01113 & 68 & 98 & 30 \\
Control Group & 84 & 77,0595 & 75 & 80,876 & 8,79931 & 60 & 95 & 35 \\
\hline
\end{tabular}

Tabel 5. Penggunaan Snake and Ladder dan Non Board Game

\begin{tabular}{lccrcrrrr}
\hline \multicolumn{1}{c}{ Group } & \multicolumn{1}{c}{$\boldsymbol{N}$} & Mean & Median & Variance & Std. Deviation & Minimum & Maximum & Range \\
\hline $\begin{array}{l}\text { Experimental } \\
\text { Group }\end{array}$ & 72 & 83,2222 & 84 & 103,161 & 10,15683 & 58 & 100 & 42 \\
Control Group & 67 & 75,4478 & 78 & 116,403 & 10,789 & 46 & 96 & 50 \\
\hline
\end{tabular}

Tabel 2 menunjukkan bahwa 85 orang siswa yang diajar dengan menggunakan Monopoly board games memperoleh skor rerata hasil belajar 84,31, sedangkan 87 orang siswa yang diajar dengan tanpa menggunakan game mendapatkan skor rerata hasil belajar 72,91. Data ini mengindikasikan bahwa siswa yang diajar dengan Monopoly board game memperoleh skor rerata lebih tinggi dibandingkan dengan mereka yang diajar tanpa game. Dari skor minimum dapat ditunjukkan bahwa siswa yang diajar dengan menggunakan Monopoly board game mendapatkan skor minimum 65, sedangkan skor minimum siswa yang tidak diajarkan dengan game mendapatkan skor minimum 46.

Tabel 3 menunjukkan bahwa 101 siswa yang diajar dengan Jigsaw Puzzle board game mendapatkan skor rerata hasil belajar 81,33, sedangkan 93 siswa yang tidak diajar dengan game mendapat skor rerata 72,24. Data tersebut menunjukkan bahwa penggunaan Jigsaw Puzzle board game pada siswa mampu mampu meningkatkan hasil belajar mereka dibandingkan dengan yang diajar tanpa game.

Tabel 4 menunjukkan bahwa 92 siswa yang diajarkan dengan Kim's board game mendapatkan skor rerata hasil belajar 82,67 , sedangkan dari 84 siswa yang tidak diajarkan dengan game mendapatkan skor rerata hasil belajar 77,05. Hal tersebut mengindikasikan bahwa Kim's board game memberikan dampak yang lebih baik pada hasil belajar siswa dibandingkan tanpa game.

Tabel 5 menunjukkan bahwa 72 siswa yang diajarkan dengan Snake and Ladder board game mendapatkan skor rerata hasil belajar 83,22, sedangkan 67 siswa yang diajarkan dengan tanpa game mendapatkan skor rerata hasil belajar 75,44, sehingga dapat disimpulkan bahwa siswa yang diajarkan dengan Snake and Ladders board game mendapatkan skor rerata hasil belajar yang lebih tinggi dibandingkan dengan siswa yang tidak diajarkan dengan game.

Tabel 6. Descriptive Statistics

\begin{tabular}{rrrrrr}
\hline & N & Mean & $\begin{array}{c}\text { Std. } \\
\text { Deviation }\end{array}$ & \multicolumn{1}{c}{$\begin{array}{l}\text { Mini- } \\
\text { mum }\end{array}$} & $\begin{array}{l}\text { Maxi- } \\
\text { mum }\end{array}$ \\
\hline Score & 681 & 78.66637 & 11.02364 & 41.00 & 100.00 \\
Group & 681 & 1.49 & .500 & 1 & 2 \\
\hline
\end{tabular}


Tabel 7. Kruskal-Wallis Test

\begin{tabular}{llrr}
\hline \multicolumn{1}{c}{ Group } & N & Mean Rank \\
\hline Score & Experimental Group & 350 & 413.29 \\
& Control Group & 331 & 264.56 \\
& Total & 681 & \\
\hline
\end{tabular}

Tabel 8. Test Statistics ${ }^{\text {ab }}$

\begin{tabular}{lr}
\hline \multicolumn{2}{c}{ Score } \\
\hline Chi-Square & 97.371 \\
Df & 1
\end{tabular}

Asymp. Sig.

.000

a. Kruskal-Wallis Test

b. Grouping Variable: group

Berdasarkan hasil analisis tes Kruskal-Wallis, dapat dilihat bahwa nilai signifikansi adalah 0,000 , lebih kecil dari 0,05 (alpha= 5\%). Hal ini berarti bahwa penggunaan board games berpengaruh signifikan terhadap hasil belajar siswa SD kelas 4, 5, 6 di Kabupaten Buleleng.

Tabel 9. Descriptive Statistics

\begin{tabular}{lrrrrr}
\hline & N & Mean & $\begin{array}{c}\text { Std. } \\
\text { Deviation }\end{array}$ & Minimum & Maximum \\
\hline Score & 172 & 78.5465 & 12.03810 & 46.00 & 98.00 \\
Group & 172 & 1.51 & .501 & 1 & 2 \\
\hline
\end{tabular}

Tabel 10. Mann-Whitney Test

\begin{tabular}{llrr}
\hline \multicolumn{1}{c}{ Group } & \multicolumn{1}{c}{$\boldsymbol{N}$} & \multicolumn{1}{c}{ Mean Rank } \\
\hline Score & Experimental Group & 85 & 9299.50 \\
& Control Group & 87 & 5578.50 \\
& Total & 172 & \\
\hline
\end{tabular}

Tabel 11. Test Statistics ${ }^{\mathrm{a}}$

\begin{tabular}{lr}
\hline & \multicolumn{1}{c}{ Score } \\
\hline Mann-Whitney U & 1750.500 \\
Wilcoxon W & 5578.500 \\
$\mathrm{Z}$ & \\
Asymp. Sig. (2-tailed) & .000 \\
\hline a. Grouping Variable: Group
\end{tabular}

Berdasarkan hasil analisis tes Mann Whitney, yang membandingkan kelompok siswa yang diajar dengan Monopoly board game dengan tanpa game, dapat dilihat bahwa nilai signifikansi adalah 0,000 , lebih kecil dari 0,05 (alpha $=5 \%$ ). Hal ini berarti bahwa Monopoly board game berpengaruh signifi- kan terhadap hasil belajar siswa SD kelas 4, 5, 6 di SD perwakilan wilayah Barat Kabupaten Buleleng.

Tabel 12. Descriptive Statistics

\begin{tabular}{lrrrrr}
\hline & $\boldsymbol{N}$ & Mean & $\begin{array}{c}\text { Std. } \\
\text { Deviation }\end{array}$ & \multicolumn{2}{c}{ Minimum Maximum } \\
\hline Score & 194 & 76.9794 & 11.57448 & 41.00 & 100.00 \\
Group & 194 & 1.48 & .501 & 1 & 2 \\
\hline
\end{tabular}

Tabel 13. Mann-Whitney Test

\begin{tabular}{llrcc}
\hline \multicolumn{1}{c}{ Group } & N & $\begin{array}{l}\text { Mean } \\
\text { Rank }\end{array}$ & $\begin{array}{l}\text { Sum of } \\
\text { Ranks }\end{array}$ \\
\hline Score & $\begin{array}{l}\text { Experimental } \\
\text { Group }\end{array}$ & 101 & 119.00 & 12018.50 \\
& & & \\
Control Group & 93 & 74.16 & 6896.50 \\
Total & 194 & & \\
\hline
\end{tabular}

Tabel 14. Test Statistics ${ }^{a}$

\begin{tabular}{lr}
\hline & \multicolumn{2}{c}{ Score } \\
\hline Mann-Whitney U & 2525.500 \\
Wilcoxon W & 6896.500 \\
Z & -5.562 \\
Asymp. Sig. (2-tailed) & .000 \\
\hline
\end{tabular}

a. Grouping Variable: Group

Berdasarkan hasil analisis tes Mann Whitney di atas, yang membandingkan kelompok siswa yang diajar dengan Jigsaw Puzzle board game dan tanpa game, dapat dibuktikan bahwa nilai signifikansi adalah 0,000, lebih kecil dari 0,05 (alpha= 5\%). Hasil ini membuktikan bahwa Jigsaw Puzzle board game berpengaruh signifikan terhadap hasil belajar siswa SD kelas 4, 5, 6 di SD perwakilan wilayah Utara Kabupaten Buleleng.

Tabel 15. Descriptive Statistics

\begin{tabular}{lrrrrr}
\hline & N & Mean & $\begin{array}{c}\text { Std. } \\
\text { Deviation }\end{array}$ & Minimum & Maximum \\
\hline Score & 176 & 79.9943 & 8.92412 & 60.00 & 98.00 \\
Group & 176 & 1.48 & .501 & 1 & 2 \\
\hline
\end{tabular}

Tabel 16. Mann-Whitney Test

\begin{tabular}{llrrr}
\hline \multicolumn{1}{c}{ Group } & N & Mean Rank & $\begin{array}{l}\text { Sum of } \\
\text { Ranks }\end{array}$ \\
\hline Score & $\begin{array}{l}\text { Experimental } \\
\text { Group }\end{array}$ & 92 & 103.52 & 9524.00 \\
& Control Group & 84 & 72.05 & 6052.50 \\
& Total & 176 & & \\
\hline
\end{tabular}


Tabel 17. Test Statistics ${ }^{a}$

\begin{tabular}{lr}
\hline & \multicolumn{2}{c}{ Score } \\
\hline Mann-Whitney U & 2482.000 \\
Wilcoxon W & 6052.000 \\
Z & -4.098 \\
Asymp. Sig. (2-tailed) & .000 \\
\hline
\end{tabular}

a. Grouping Variable: Group

Berdasarkan hasil analisis tes Mann Whitney di atas, yang membandingkan kelompok siswa yang diajar dengan Kim's board game dan tanpa game, dapat dilihat bahwa nilai signifikansi adalah 0,000 , lebih kecil dari 0,05 (alpha $=5 \%)$. Hal ini berarti bahwa Kim's board game berpengaruh signifikan terhadap hasil belajar siswa SD kelas 4, 5, 6 di SD perwakilan wilayah Timur Kabupaten Buleleng.

Tabel 18. Descriptive Statistics

\begin{tabular}{lrrrrr}
\hline & N & Mean & $\begin{array}{c}\text { Std. } \\
\text { Deviation }\end{array}$ & Minimum & Maximum \\
\hline Score & 139 & 79.4748 & 11.13314 & 46.00 & 100.00 \\
Group & 139 & 1.48 & .501 & 1 & 2 \\
\hline
\end{tabular}

Tabel 19. Mann-Whitney Test

\begin{tabular}{llrrc}
\hline \multicolumn{1}{c}{ Group } & N & $\begin{array}{c}\text { Mean } \\
\text { Rank }\end{array}$ & $\begin{array}{l}\text { Sum of } \\
\text { Ranks }\end{array}$ \\
\hline Score & Experimental & 72 & 82.91 & 5969.50 \\
& Group & & & \\
Control Group & 67 & 56.13 & 3760.50 \\
Total & 139 & & \\
\hline
\end{tabular}

\section{Tabel 20. Test Statistics ${ }^{a}$}

\begin{tabular}{lr}
\hline & \multicolumn{1}{c}{ Score } \\
\hline Mann-Whitney U & 1482.500 \\
Wilcoxon W & 3760.500 \\
Z & -3.924 \\
Asymp. Sig. (2-tailed) & .000 \\
\hline
\end{tabular}

a. Grouping Variable: Group

Berdasarkan hasil analisis tes Mann Whitney di atas, yang membandingkan kelompok siswa yang diajar dengan Snake Ladder board game dan tanpa game, dapat dibuktikan bahwa nilai signifikansi adalah 0,000, lebih kecil dari 0,05 (alpha= 5\%). Hasil ini membuktikan bahwa Snake Ladder board game berpengaruh signifikan terhadap hasil belajar siswa SD kelas 4, 5, 6 di SD perwakilan wilayah Selatan Kabupaten Buleleng.

Dari semua analisis data inferensial di atas, dapat disimpulkan bahwa penggunaan board games dalam pembelajaran Bahasa Inggris berpengaruh terhadap hasil belajar siswa kelas 4, 5, dan 6 di semua SD perwakilan wilayah Barat, Timur, Utara, dan Selatan di Kabupaten Buleleng.

\section{Pembahasan}

Mengacu pada semua temuan di atas, data analisis tes Kruskal-Wallis menunjukkan bahwa terdapat pengaruh yang signifikan dari pemanfaatan board games terhadap hasil belajar siswa. Begitu pula analisis dengan Mann-Whitney juga membuktikan bahwa masing-masing jenis board games, yaitu Monopoly, Jigsaw Puzzle, Snake and Ladder, dan Kim's berpengaruh signifikan terhadap hasil belajar siswa. Hasil ini membuktikan bahwa games memang cocok untuk peserta didik anak-anak. Hal ini mendukung pendapat Feez (2010) dan Brewster, dkk. (2007) bahwa games merupakan fondasi pembelajaran untuk anak-anak dan bagus untuk perkembangan siswa secara holistik dalam tiga aspek yaitu kognitif, psikomotor, dan afektif. Hasil penelitian ini juga mendukung pendapat Paul (2003) dan Wright, dkk. (2006) bahwa games merupakan cara yang terbaik untuk membuat siswa terlibat secara intensif dalam pembelajaran, dapat membantu dan mendorong mereka untuk mempertahankan ketertarikan dan aktivitas belajarnya. Hasil penelitian ini juga mendukung penelitian sebelumnya (Ratminingsih, 2014) bahwa hasil belajar peserta didik anak-anak dapat ditingkatkan dengan menggunakan strategi yang menyenangkan. Perbedaannya adalah penelitian sebelumnya menekankan pada penggunaan lagu kreasi.

Dalam kegiatan pembelajaran dengan games, peserta didik terbukti semangat berpartisipasi aktif dan mereka tertantang untuk mampu memahami apa yang dijelaskan oleh guru agar dapat memecahkan masalah dalam games. Mereka juga tertantang untuk belajar berbicara (menyebutkan) dan menulis kata-kata yang diinstruksikan dalam board games. Selain belajar melafalkan kata-kata, mereka juga dilatih bercakap-cakap sederhana, sehingga dengan menggunakan games, mereka bukan hanya belajar tentang bahasa, tetapi juga belajar menggunakan bahasa. Hal ini sesuai dengan pendapat Ebrahimi dan Zamanian (2014) bahwa melalui penggunaan games, peserta didik dapat meningkatkan perhatiannya dan berpartispasi dalam pembelajaran, dan yang terpenting adalah dapat mengembangkan aktivitas mental dan fisik.

Berdasarkan hasil penelitian yang telah dipaparkan di atas, dapat dikatakan bahwa penelitian ini mendukung penelitian Wang, Shang, dan Briody (2011) yang membuktikan bahwa terdapat hubung- 
an positif dan signifikan antara penggunaan games dan motivasi siswa dalam belajar. Gawi, (2012), Mart (2012), Mahmound dan Tanni (2014), dan Hosni (2014) juga membuktikan bahwa games dapat meningkatkan motivasi siswa dalam belajar bahasa Inggris. Selanjutnya, Lee dan Lester (2012) membuktikan bahwa siswa memiliki sikap positif terhadap pemanfaatan board games, yaitu SMARTies, dalam pembelajaran bahasa Inggris sebagai bahasa kedua, yang mana oleh Griva, Semoglou, dan Geladari (2010) ditegaskan bahwa games dapat meningkatkan kompetensi sosial, yaitu belajar secara kooperatif dan interaktif yang dapat meningkatkan kompetensi berkomunikasi. Sependapat dengan Berland dan Lee (2012), Griva, dkk. (2010), dan Zagal, dkk. (2006) membuktikan bahwa games khususnya board games memiliki potensi kuat untuk membuat peserta didik beraktivitas secara kolaboratif dalam proses pemahaman pengetahuan. Lee dan Lester (2012) dan Ramani, Hitti, dan Siegler (2012) juga membuktikan bahwa penggunaan board games dapat meningkatkan pengetahuan, yang dalam penelitian Ramani, dkk. (2012) berupa pengetahuan numerikal, sedangkan dalam penelitian Lee dan Lester (2012) berupa kemampuan mengingat istilah-istilah dan konsep utama dalam bahasa target, yang sama dengan penelitian ini, yakni menekankan pada pengetahuan kebahasaan, yaitu penguasaan materi yang diajarkan, seperti kosakata dan gramatika yang terkait dengan tema-tema yang harus diajarkan dalam konteks kelas, sekolah, dan lingkungan sekitar.

Secara lebih khusus, hasil penelitian ini juga mendukung penelitian Masri dan Najar (2014), Keshta dan Al-Faleet (2013), Tuan (2012), dan Wang, dkk. (2011) yang menunjukkan bahwa $g a$ mes dapat meningkatkan pengetahuan siswa terutama dalam kosakata. Pengetahuan kosakata dapat dengan lebih cepat dipahami dan lama tersimpan dalam memori siswa, oleh karena mereka dibantu memvisualisasikannya dalam bentuk permainan, khususnya board games.

Hasil penelitian ini juga mendukung penelitian Yolageldili dan Arikan (2011) yang membuktikan efektivitas penggunaan games dalam mengajar grammar kepada peserta didik anak-anak. Melalui games, siswa mempelajari grammar dengan cara yang lebih menyenangkan dan dalam konteks belajar yang bermakna dan komunikatif. Siswa yang kurang mampu secara kognitif dapat belajar dari siswa yang lebih mampu melalui kerjasama dan interaksi mereka dalam games. Hasil penelitian ini juga mendukung penelitian yang dilakukan sebelumnya oleh Ratminingsih (2012) yang membuk- tikan bahwa games merupakan salah satu teknik pembelajaran yang efektif dalam pembelajaran keterampilan berbahasa (language skills) khususnya keterampilan mendengarkan. Pemanfaatan games dalam pembelajaran terutama memberikan pengaruh yang signifikan pada siswa yang bertipe kepribadian introversi, yakni mereka yang kurang senang bergaul, kurang suka berkomunikasi. Hasil penelitian ini juga mendukung temuan Oktavianingsih (2012) yang membuktikan bahwa game khususnya snake and ladder dapat meningkatkan kemampuan berbicara. Hasil penelitian ini juga membuktikan bahwa games yang dikembangkan oleh Ratminingsih dan Budasi (2015) terbukti efektif meningkatkan hasil belajar bahasa Inggris siswa di kelas 4, 5 , dan 6 .

Berdasarkan pembahasan di atas, dapat disimpulkan bahwa memang benar faktor psikologis siswa, yaitu perhatian, ketertarikan, dan sikap positif mereka terhadap pembelajaran berpengaruh terhadap hasil belajar (Kpolovie, dkk., 2014). Faktor psikologis tersebut dapat dibantu pemaksimalannya melalui pemanfaatan fasilitator pembelajaran berupa media permainan, yaitu board games, yang mampu mengajak peserta didik anak-anak untuk terlibat secara mental dan fisik dalam proses pembelajaran yang menyenangkan, sehingga hasil belajarnya menjadi efektif dan efisien serta meningkatkan kualitas pembelajaran (Rao, 2014; Syandri, 2015).

\section{SIMPULAN}

Berdasarkan hasil penelitian yang telah diuraikan di atas, dapat disimpulkan bahwa penggunaan media pembelajaran yang relevan, dalam hal ini board games, berpengaruh terhadap hasil belajar Bahasa Inggris siswa sekolah dasar. Masing-masing jenis board game, yaitu Monopoly, Jigsaw Puzzle, Kim's, dan Snake and Ladder juga terbukti berpengaruh terhadap hasil belajar Bahasa Inggris. Jadi, media pembelajaran yang tepat memang terbukti mampu meningkatkan hasil belajar.

Dengan demikian, disarankan kepada para guru pengampu mata pelajaran Bahasa Inggris di sekolah dasar agar dapat memaksimalkan penggunaan board games dalam memvariasikan pembelajaran dan memotivasi siswa. Melalui games, mereka dapat terlibat lebih aktif dalam usaha memecahkan masalah dalam permainan, bekerja bersama dengan teman sambil belajar menggunakan bahasa dalam kegiatan berkomunikasi dengan cara yang menyenangkan. Bila mereka sudah senang dan tertarik belajar, maka mereka akan dapat meningkatkan hasil belajarnya. 


\section{DAFTAR RUJUKAN}

Ana, I.K.T.A. \& Ratminingsih, N.M. 2012. Teaching English Tenses to EFL Learners: Deductive or Inductive? International Journal for CrossDisciplinary Subjects in Education, 2(2): 9981004.

Awan, R., Noureen, G., \& Naz, A. 2011. A Study of Relationship between Achievement Motivation Self-Concept and Achievement in English and Mathematics at Secondary Level. Canadian Center of Science and Education, 4(3): 72-79.

Benzies, Y.J. 2015. Using Traditional Board Games in EFL Classes to Focus on Pronunciation. Humanising Language Teaching, (Online), Vol. 17, No. 1, http://www.hltmag. co.uk/feb15/ mart01.htm), diakses 22 Agustus 2016.

Berland, M. \& Lee, V.R. 2011. Collaborative Strategic Board Games as A Site for Distributed Computational Thinking. International Journal of GameBased Learning, 1(2): 65-81.

Brewster, J., Ellis, G. \& Girard, D. 2007. The Primary English Teacher's Guide. Essex, England: Pearson Education Limited.

BSNP. 2006. Standar Isi untuk Satuan Pendidikan Dasar dan Menengah, Jakarta: Badan Standar Nasional Pendidikan.

Chitravelu, N., Sithamparam, S., \& Choon, T. S. 2005. ELT Methodology Principles and Practice. Malaysia: Oxford Fajar Sdn.Bhd.

Ebrahimi, F. \& Zamanian, M. 2014. Practical Game: Implementing Practical Game on Iranian Early EFL Learners. International Journal of English and Education, 3(2): 115-131.

Erdogan, Y., Bayram, S., \& Deniz, L. 2008. Factors that Influence Academic Achievement and Attitude in Web Based Education. International Journal of Instruction, 1(1): 31-48.

Ersoz, A. 2008. From Six Games for the EFL/ESL Classroom. The Internet TESL Journal 6 (6): 1-4.

Feez, S. 2010. Montessori and Early Childhood. London: SAGE Publications Ltd.

Feng, H.Y., Fan, J.J., \& Yang, H.Z. 2013. The Relation of Learning Motivation And Achievement in EFL: Gender as An Intermediated Variable. Educational Research International, 2(2): 50-58.

Garrett, T. 2008. Student-Centered and TeacherCentered Classroom Management: A Case Srudy of Three Elementary Teachers. Journal of Classroom Interaction, 43(1): 34-47.

Gawi, E.M.K. 2012. The effect of Age Factor on Learning English: A case Study of Learning English in Saudi Schools, Saudi Arabia. English Language Teaching, 5(1): 127-139.

Griva, E., Semoglou, K. \& Geladari, A. 2010. Early Foreign Language Learning: Implementation of A Project in A Game-Based Context. Procedia Social and Behavioral Sciences 2(2): 3700-3705.
Hosni, S.A. 2014. Speaking Difficulties Encountered By Young EFL Learners. International Journal on Studies in English Language and Literature, 2(6): 22-30.

Keshta, A.S. \& Al-Faleet, F.K. 2013. The Effectiveness of Using Puzzles in Developing Palestinian Tenth Graders' Vocabulary Achievement and Retention. Humanity and Social Sciences Journal, 1(1): 46-57.

Kpolovie, P.J., Joe, A.I. \& Okoto, T. 2014. Academic Achievement Prediction: Role of Interest in Learning and Attitude towards School. International Journal of Humanities Social Sciences and Education, 1(11): 73-100.

Lee, H. \& Lester, J. 2012. SMARTies: Using Board Game in the English Classroom for Edutainment and Assessment. Malaysian Journal of ELT Research, 8(1): 1-11.

Mahmound, A., \& Tanni, Z. 2014. Using games to Promote Students' Motivation toward Learning English. Al-Quds Open University Journal for Educational and Psychological Research and Studies, 2(5): 13-30.

Mart, C.T. 2012. Encouraging Young Learners to Learn English through Stories. English Language Teaching, 5(5): 101-106.

Masri, A. \& Najar, M. 2014. The effect of Using Word Games on Elementary Stage Students' Achievement in English Language Vocabulary in Jordan. American International of Contemporary Research, 4(9): 144-152.

Moursund, D. 2007. Introduction to Using Games in Education: A Guide for Teachers and Parents. Oregon: University of Oregon.

Munoz, C. 2014. Starting Age and Other Influential Factors: Insights from Learner Interviews. Studies in Second Language Learning and Teaching, 4(3): 465-484.

Naz, A. A. \& Akbar, R. A. 2012. Use of Media for Effective Instruction Its Importance: Some Consideration. Journal of Elementary Education, 18(12): 35-40.

Oktavianingsih, T. 2012. Using "Snake Ladder" Game to Increase the Speaking Ability of Eighth Grade of Junior High School in MTs Futuhiyyah 2 Mirranggen 2011/2012. Tesis tidak diterbitkan. Semarang: IKIP PGRI Semarang.

Paul, D. 2003. Teaching English to Children in Asia. Hong Kong: Pearson Education Asia Ltd.

Ramani, G.B., Hitti, A. \& Siegler, R.S. 2012. Taking it to the Classroom: Number Board Games as A Small Group Learning Activity. Journal of Education Psychology, 104(3): 661-672.

Ramendra, D.P. \& Ratminingsih, N.M. 2007. Pemanfaatan Audio Visual Aids (AVA) dalam Proses Belajar Mengajar Mata Pelajaran Bahasa Inggris 
di Sekolah Dasar. Jurnal Penelitian dan Pengembangan Pendidikan, 1(2): 78-95.

Rao, B.M. 2014. Use of Media as an Instructional Tool in English Language Teaching (ELT) at Undergraduate Level. International Journal of English and Literature, 5(6): 141-143.

Ratminingsih, N.M. 2012. Teaching Techniques, Types of Personality, and English Listening Skill. Jurnal Ilmu Pendidikan, 18(1): 23-29.

Ratminingsih, N.M. 2014. Pengembangan Model Pembelajaran Bahasa Inggris Induktif Berbasis Lagu Kreasi. Jurnal Ilmu Pendidikan, 20(1): 47-58.

Ratminingsih, N.M. \& Budasi, I G. 2015. Pengembangan Games Berorientasi Model PAKEM dalam Pembelajaran Bahasa Inggris di Sekolah Dasar. Laporan penelitian tidak dipublikasikan. Singaraja: Universitas Pendidikan Ganesha.

Sauve, L., Renaud L., Kaufman, D., \& Marquis, J. S. 2007. Distinguishing between Games and Simulations: A Systematic Review. Educational Technology and Society, 10(3): 247-256.

Schmid, M. 2016. The Best Age to Learn a Second Language, (Online), (http://www.independent.co.uk/ news/education/the-best-age-to-learn-a-secondlanguage-a6860886.html), diakses 22 Agustus 2016.
Syandri, G. 2015. A case Study on the Use of Visual Media in English Instructional Process at State Islamic Secondary School 1 Malang. Journal of Research and Method in Education, 5(4): 46-56.

Thanh, P.Y.H. 2010. Implementing a Student-Centered Learning Approach at Vietnamese Higher Education Institutions. Journal of Future Studies, 15(1): 21-38.

Tuan, L. T. 2012. Vocabulary Recollection through Games. Theory and Practice. Language Studies. 2(2): 257-264.

Wang, Y. J., Shang, H. F. \& Briody, P. 2011. Investigating the Impact of Using Game in Teaching Children English. International Journal of Learning \& Development. 1(1): 127-141.

Wright, A., Betteridge, D. \& Buckby, M. 2006. Games for Language Learning. Cambridge: Cambridge University Press.

Yolageldili, G. \& Arikan, A. 2011. Effectiveness of Using Games in Teaching Grammar to Young Learners. Elementary Education Online, 10(1): 219-229.

Zagal, J., Rick, J. \& His, I. 2006. Collaborative Games: Lesson Learned from Board Games. Simulation and Gaming, 37(1): 24-40. 